\title{
A GEOGRAFIA FÍSICA E O OBJETO COMPLEXO: ALGUMAS FLEXIBILIZAÇÕES DO PROCESSUAL.
}

\author{
*Rodrigo Dutra Gomes. \\ **Antonio Carlos Vitte.
}

O objeto complexo refere-se ao reconhecimento, enquanto princípio, ou paradigma, de que o objeto do conhecimento científico é uma entidade complexa, em ampliação à visão de objeto simples herdada da Renascença e Iluminismo. A Geografia sempre viveu a influência paradigmática moderna. Em prosseguimento ao século XIX, os avanços iniciais do século XX que corroboraram essa ampliação, como a Relatividade, Teoria Quântica e Teorias Sistêmicas etc, foram refletidas na Geografia pelos protagonistas da Revolução Quantitativo e Teorética, e na Geografia Física, por exemplo, pelas proposições de A. Strahler na Geomorfologia, ambos na década de 50. Os avanços de campos como os Sistemas Dinâmicos Não-Lineares e Física do Nãoequilíbrio, contextualizados nos sistemas dinâmicos complexos, trazem a corroboração da complexidade do objeto do conhecimento. Flexibiliza-se, numa realidade fundamentalmente 'processual', as referências duais do conhecimento que são vividas dicotomicamente. Pretende-se, de forma breve, apresentar este contexto e algumas influências na Geografia Física com realce para a Geomorfologia. Para este sub-campo, em expressão a uma tendência geral, reconhece-se a flexibilização e fluidez das entidades forma/processo e abordagens geohistóricas/funcionais-dinâmicas, em favor de uma perspectiva organizacional.

Palavras Chaves: Geografia Física, objeto complexo, processual, perspectiva organizacional.

\section{INTRODUÇÃO}

O século XX apresentou-se como um período de transição, ainda inacabado, de uma visão científica estática e mecânica para uma processual e orgânica. A Teoria da Relatividade, a Física Quântica e as Teorias Sistêmicas do início do século, vieram, na esteira da eletrodinâmica e termodinâmica antes delas no XIX, corroborar a concepção de realidade como essencialmente processual. Como outras ciências, a Geografia viveu muita da influência do movimentado início do século XX nas reflexões e acontecimentos em torno da Revolução Quantitativo e Teorética da década de 50. Mas, por fundamentais, as heranças paradigmáticas mecanicistas de fundos renascentistas e iluministas, expressas em noções como equilíbrio, estabilidade, simplicidade, homogeneidade etc, que, genericamente contextualizaremos como 'objeto (do conhecimento) simples', ainda continuam influenciando as condutas teóricas e práticas de elaborações e manuseio dos modelos.

*Doutor em Geografia pelo IG/UNICAMP. Prédio da Pós-graduação do Instituto de Geociências da UNICAMP, Cidade Universitária Zeferino Vaz, Campinas, CEP 13083970, Caixa Postal: 6152 - dutra@ige.unicamp.br

** Prof. Dr. Departamento de Geografia do IG/UNICAMP - acvitte@ige.unicamp.br 
Avanços científicos ocorridos depois da década de 50 nos campos dos Sistemas Dinâmicos Não-lineares e Física do Não-equilíbrio trouxeram incrementos descritivos e ampliações nestas concepções paradigmáticas via noções como instabilidade, bifurcações, caos, fractais, auto-organização etc, reconhecendo o caráter 'complexo' do objeto do conhecimento. Esses são os conhecimentos que remetem aos chamados Sistemas Dinâmicos Complexos e o contexto da Complexidade, com perspectivas conciliatórias entre o explanativo e interpretativo, nomotético e idiográfico, naturezacausal e humano-histórico, e de forma mais ampla entre as Ciências e Humanidades. A Geografia, assim como os diversos campos do conhecimento, vem se nutrindo de forma inicial das repercussões advindas deste contexto. Mais focada na funcionalidade espacial dos sistemas físicos-naturais na integração com o humano, a Geografia Física, tem, em seus diversos ramos - Geomorfologia, Hidrologia, Pedologia, Climatologia etc - muito se alimentado destes avanços. Entretanto, mesmo que localizada em situação estratégica a todo esse contexto, na encruzilhada entre o Humano e o Natural, o Idiográfico e o Nomotético, Interpretativo e o Explanativo, Ciências e Humanidades, ainda são iniciais as reflexões e repercussões epistemológicas para a Geografia em geral. Pretende-se oferecer alguns entendimentos que reconheçam flexibilizações às persistentes dicotomias epistemológicas, como nomotético/idiográfico, e ontológicas, como as escalas macro/micro, total/individual e domínios causais/comportamentais, direcionado, em perspectiva, para o diálogo entre abordagens e métodos. Para a Geografia Física realça-se a importância dos trabalhos de campo para verificação das 'entidades e relações' envolvidas na manifestação do objeto de estudo, entendido e descrito como de caráter 'complexo'. Tais considerações inserem-se nas perspectivas de ampliações do arcabouço teórico reflexivo de manuseio dos modelos práticos.

\section{AS HERANÇAS CARACTERISTICAS DO OBJETO 'SIMPLES'.}

Por 'objeto simples' estamos denominando a concepção moderna que atribui uma propriedade dinâmica fundamentalmente simples, mensurável, delimitável ao objeto do conhecimento científico. Esta é uma das expressões que pode ser contextualizada em princípios balizares que foram forjadas no período da Renascença e Iluminismo e que bem expressam a forma moderna de se conceber a constituição e funcionamento do Mundo. Por fundamentais, estas bases representam importantes estruturas guias, que, de forma inerente, bem influenciam a conduta científica reflexiva e prática. Estas foram, principalmente ao longo do século $\mathrm{XX}$, sendo questionados e ampliados em suas concepções em favor de perspectivas mais 'complexas'. Então, apresentemos de forma básica, algumas das concepções paradigmáticas que expressam essa concepção 'simples' de Mundo. As referências para tais concepções podem ser encontradas em autores como Morin (1996, p.329), Morin \& Le Moigne (2000, p.45), Santos (1998, 58p.), Vasconcellos (2002, 268p) etc.

Cita-se, inicialmente o paradigma da simplicidade que traz, justamente, essa idéia de que o objeto de pesquisa é simples, o que se reflete nas várias denominações atribuídas, no início da ciência moderna, às propriedades de inteligibilidade dos objetos da natureza, como, por exemplo, as idéias de estabilidade, equilíbrio, uniformidade, identidade, homogeneidade, continuidade, inalterabilidade, etc. Este paradigma obteve uma de suas expressões fundamentais na proposta metodológica de René Descartes (1596-1650) em seu Discurso do Método, iniciando, neste, seu procedimento analítico 
de grande sucesso. No método cartesiano, expressa-se o paradigma da separabilidade. Por esse o objeto complexo é fragmentado em tantas parcelas quanto for possível e necessária para o seu inquérito, muitas vezes, isolando-o de seu ambiente em laboratórios, consultórios etc, tratando-o como entidade individual. Acende-se, a partir do entendimento obtido, das parcelas mais simples para as mais compostas, seguindo de suas classificações e compartimentação em categorias, e que muitas vezes podem ser tratadas como excludentes entre si.

Segue-se o paradigma da 'universalidade', com o conhecimento científico aspirando a generalidade e procurando sempre descobrir as regras gerais fixas, as Leis, que regem o funcionamento do conjunto ao qual um objeto se condiciona, e que teve nas concepções absolutas do Espaço e Tempo de Newton, transpassadas para Kant, as absolutas e seguras balizas de apoio para tal empresa. $O$ universo mecanicista no período de consolidação da ciência moderna concebia também o paradigma da 'ordem, estabilidade e equilíbrio' como soberanos na dinâmica da natureza. O Determinismo e as leis da causalidade linear são umas das principais expressões de tal concepção, pela qual se coaduna a idéia de descoberta das leis ou regras fixas dos fenômenos. O universo obedeceria nestes termos às leis determinísticas que possibilitariam, por sua vez, uma perfeita descrição pelos vieses matemáticos e lógicos, como, por exemplo, acontece na descrição dos movimentos de um objeto em termos de trajetórias (x y z), ponto a ponto, num espaço euclidiano. Destaca-se, neste seguimento, o paradigma que confia absolutamente na lógica e matemática. A matematização do projeto científico, como exemplo, veio no sentido de pautar o conhecimento científico num modelo considerado como verdadeiro e rigoroso, e aplicável a todos os domínios. Sobre estas bases Descartes resgatou à chamada Mathesis Universalis (Matemática Universal), de fundos na Antiguidade. Esta refere-se à existência de uma ciência geral que toma a 'ordem e medida' como referência, e que explicaria tudo o que é possível investigar. Sem especificar o tipo de matéria tratada, considerou-se que, todas as coisas que se observa uma ordem e medida se reportariam, necessariamente, à descrição segura da matemática.

Outro paradigma típico, que coaduna com a simplicidade do objeto é o reducionismo. Dele decorre a operação da redução, que procura reduzir o objeto complexo a um outro mais simples e bem conhecido, submetendo o entendimento do conjunto do objeto à suas partes constituintes, como é o caso, por exemplo, de se reduzir a vida às suas características bioquímicas, ou o indivíduo aos processos sociais. Seguese a 'objetividade' científica que buscou, nesta esteira, sob referências absolutas, conhecer a realidade livre de qualquer subjetividade ou influência ideológica, confiando obter um conhecimento seguro e verdadeiro, e que fomentou a pretensão de constituir, a ciência, um saber monístico, o único e verdadeiro do mundo.

Lembra-se que o conhecimento ocidental referencia-se em dualidades, tendo a interpretação que o homem moderno dá a sua situação existencial, como não pertencente, ou exterior, à Natureza, uma das principais expressões de tal forma de pensamento. Com isso, a disjunção existencial do Homem perante a Natureza, mascarada no conhecimento como sujeito e objeto, expressa-se epistemologicamente no paradigma que carrega a 'exclusão da noção de ser e existência' que foram considerados como desprovidos de valor prático e efetivo no inquérito científico da realidade.

Sob as referências duais, estes paradigmas, que se interconectam e justificam, favoreceram a especialização e incomunicabilidade do conhecimento. Sob vivências dicotômicas das balizas duais, como nomotético/idiográfico, sistemático/regional, 
causal/comportamental, processo/forma, total/local, espaço/lugar etc, ocorre, sob estas referências, a incomunicabilidade prática entre as formas de conhecimento epistemologias, abordagens, procedimentos, teorias, modelos etc - pelas suas aplicações unilaterais.

\section{A INERÊNCIA NA GEOGRAFIA FÍSICA}

A Geografia, como legítima representante do conhecimento ocidental moderno, sempre viveu de forma inerente as influências paradigmáticas e duais fundamentais. Para adentrarmos na Geografia Física tomaremos a Geomorfologia como referência, em vista ser um dos campos dos estudos ambientais com maior aprofundamento teórico metodológico. A influência da concepção de objeto simples pode ser balizada nas vivências epistemológicas duais em remetimento a noção de "equilíbrio". Esta é uma referência básica para os estudos ambientais e geomorfológicos, e, por esta noção bem expressa-se a influência imperativa do paradigma da ordem e estabilidade do mundo, característico de uma visão mecanicistas e que detém ainda poderosa influência nas reflexões e condutas.

Duas correntes básicas podem ser discernidas na geomorfologia, as abordagens funcionais-dinâmicas e as evolutivas-históricas. Dentro da primeira concepção inseremse a tradição de autores clássicos que vão desde James Hutton (1726-1797), Charles Lyell (1797-1875), J.L. Agassis (1807-1873), A. C. Ramsay (1814-1891), F. V. Ritchthoffen (1833-1905), Gilbert (1843-1918) e os mais modernos como Arthur Strahler e Richard Chorley, estes dois últimos serão melhor contextualizados a seguir. Em relação aos autores clássicos todos são membros da tradição "dinâmica", que considera o objeto como eterno (a-histórico, timeless), dando relevância principalmente para os 'processos' responsáveis pelas configurações do terreno. Contudo, existiu entre os 'dinâmicos a-históricos' dois cursos de pensamento, a saber, sobre a 'evolução' do relevo: a descrição em termos de seqüência versus a de progressão. A primeira representa o papel do presente como vital para tipo de relevo do passado, e o segundo com o passado sendo o precursor do presente. Essa separação vincula-se a dois respectivos grupos de atitudes, ambas ligadas à significância dada aos eventos raros e cataclísmico, com os primeiros dando maior flexibilidade sobre eles (Hutton, Gilbert), e os segundos, progressistas, mais ligados à evolução suave dos processos, com realce às leis dinâmicas universais (Lyell, Horton). Mesmo com divergências, convergem todos no sentido de explicar as formas de relevo a partir dos processos, vinculados ao lado funcional dos termos dicotômicos. Destes, Gilbert foi quem reconheceu a importância do conceito de equilíbrio em 1880. Considerando os elementos fluviais e os das vertentes como integrados em um sistema interrelacionado, nele, o conceito de equilíbrio significava que os materiais, processos e a geometria do modelado, compunham um conjunto auto-regulador, com toda forma sendo o produto do ajustamento entre materiais e processos (KENNEDY, 1992, p.246).

A perspectiva histórico-evolutiva tem, por seu lado, em W. M. Davis (18501934) a sua principal figura representativa com o Ciclo da Erosão. A teoria da evolução biológica de Darwin e a 2 a Lei da termodinâmica, com a noção de entropia, desempenharam influências marcantes nas proposições davisianas. O termo entropia foi cunhado por R. Clausius (1822-1888) como uma quantidade que mede o grau de evolução de um sistema, sempre indo, unidirecionalmente, de um estado potencial (ordem) para um estado dissipado (desordem), correspondente este ao estado de 
"equilíbrio termodinâmico". Influentes nas ciências em geral, estas elaborações estabeleceram-se como guias para a proposição de hipóteses e teorias, o que destacou, no período, a idéia de evolução e historicidade, em ampliação à visão eterna (ahistórica, timeless) da concepção dinâmica. Sob estas e outras influências a proposta de Davis constitui um modelo teórico que correspondia à construção de séries evolutivas de formas-tipos. Fazendo analogias biológicas, com respeito à evolução do nascimento à morte, designa, em tons antropomórficos, a seqüência de fases pela qual passa o modelado terrestre, denominando-os de juventude, maturidade e senilidade. A idéia do ciclo da erosão resume-se basicamente em uma superfície plana que foi deformada bruscamente por uma ação tectônica e, sobre o relevo então formado, age-se a erosão que o reduz, lenta e progressivamente, através destas fases, até a formação de uma superfície plana, pouco acima do nível do mar, correspondente ao nível de base da erosão de Powell, conceitualizado de peneplanície por Davis, e que corresponde ao ponto de partida para o novo ciclo a evoluir. Esta concepção teórico-metodológica foi muito influente ao longo de todo o século XX (CHRISTOFOLETTI, 1980, p.16).

A partir de 50, a geomorfologia sofreu as influências advindas dos avanços e rupturas científicas do início do século, com o reconhecimento de uma realidade fundamentalmente processual que serão comentados a seguir. Se Schaeffer representou essa influência para a Geografia em 1953, Arthur Strahler (1918-2002), um ano antes, propôs uma nova atitude epistemológica para os estudos geomorfológicos. Em renúncia à abordagem histórico-evolucionista de Davis, Strahler veio dar nova ênfase para os estudos dos processos, vinculados agora a uma abordagem mais quantitativa sob ferramental estatístico. Tal abordagem matemática já constava em Gilbert, a novidade de Strahler foi o de buscar determinar, a partir destas ferramentas, as relações entre os processos e as formas. Estabeleceu-se nele uma relação mais estreita com as ciências físicas e químicas, colocando as Teorias Sistêmicas como as referências guias das reflexões dos processos geomorfológicos, utilizando-se de sua terminologia. Outras teorias que podem ser citadas dentro desta perspectiva é a do "Equilíbrio Dinâmico" de John T. Hack, a "Probabilística" de Luna B. Leopold e W. B. Langbein de 1962, e as "proposições sistêmicas" de Richard J. Chorley, oferecendo eles novas perspectivas de tratamento geomorfológico, agora em termos processuais e que veio a ganhar maior notoriedade e expansão somente a partir da década de 70 (SACK, 1992, p.255). A introdução destas teorias na análise do relevo levou a uma retomada e revisão da noção de equilíbrio, considerada agora como representando o ajustamento completo das variáveis internas do sistema às suas condições de interação externas. Neste dinamismo, considera-se que o sistema pode chegar ao chamado steady-state, estado quando os parâmetros entre as trocas de energia e matéria do sistema permanecem constantes, de forma que, retomou-se a terminologia que negligencia a dimensão histórica temporal (ahistórica, timeless) dos processos. Contudo, mesmo contrapondo-se à abordagem davisiana, Strahler já reconhecera que na realidade a abordagem geomorfológica pode não divorciar-se totalmente da abordagem histórica-evolucionista e da descrição das singularidades de manifestação que ela implica, por serem parecidas como inerentes à manifestação do fenômeno geomorfológico.

Re-expressa-se, então, nas últimas décadas do século XX, a dualidade epistemológica vivida dicotomicamente: funcional/histórica. No panorama que se estabeleceu destacam-se as contribuições de Schumm \& Lichty (1973, p.44) que, inseridos na perspectiva sistêmica-funcional-processual, buscaram resolver tal controvérsia dicotômica de mútuas exclusões entre as abordagens escalares. Procuraram 
eles demonstrar que nos estudos processuais, em perspectiva sistêmica, deve-se, na verdade, procurar relatar os níveis de causalidades envolvidas no fenômeno, para que, com isso, possa-se distinguir a forma, ou abordagem, mais adequada para se descrever e vislumbrar a evolução do sistema. Os autores relevam que a distinção entre causa e efeito no modelado das formas de relevo depende do espaço de tempo envolvido e da grandeza do sistema geomórfico em consideração. A causalidade pode, assim, muito bem variar em dependência do tempo e do tamanho (espaço) da área de pesquisa considerada, de forma que, desde que se alterem estas dimensões, as relações de causa e efeito podem ser obscurecidas e até mesmo revertidas, de maneira que a descrição do sistema pode muito bem variar de acordo com a escala adotada. Isso se dá por que os fatores que determinam, por exemplo, o caráter das formas de relevo, podem ser ambos, tanto variáveis dependentes, quanto variáveis independentes, de acordo com os limites estabelecidos de mudanças no tempo e no espaço considerados. Dessa forma, a concepção a-histórica é revertida e provoca 'aprisionamentos' temporais, onde os aspectos históricos e processuais influentes em determinadas escalas podem, em certos casos, ser negligenciados em outras.

Com respeito aos modelos de estudos ambientais, a aplicação dos modelos na segunda metade do século XX, agora sob o predomínio do método hipotético-dedutivo, manteve este inerente vinculo aos paradgimas modernos e noção de equilíbrio, obtendo com eles um parâmetro de controle e previsão dos estados prováveis do sistema; como é o caso dos modelos conceituais como o Geossitema de Sotchava e Bertrand, o Ecodinâmico de Tricart, e as metodologias integradas do meio ambiente de M. Penteado Orellana e C. A. F. Monteiro. Em termos sistêmicos pode-se dizer que houve o realce das características de estabilização da descrição do objeto, relevando os mecanismos corretores das perturbações infligidas, os feedbacks negativos. Assim, nos estudos geossistêmicos, sob heranças que perpetuam as dicotomias, os fatores humanos são considerados como 'perturbadores' de um 'equilíbrio' pré-existente e pré-concebido dos sistemas físicos-naturais.

Remetendo, agora às proposições de Bertrand (1972, p.09) a dinâmica de equilíbrio dos sistemas ambientais é concebida sob a influência biológica, ou biogeográfica, das noções de biostasia e resistasia de Erhart, com a primeira referindose basicamente a uma dinâmica estável onde os processos pedogenéticos de formação de solo são predominantes, e o segundo referente à uma dinâmica desequilibrada em busca de estabilização, quando os processos morfogenéticos (alteração de formas) prevalecem, como no caso dos processos erosivos decorrentes da desmedida ocupação e utilização do solo. Tricart (1977, p.35), por sua vez, buscando um sistema de 'classificação ecodinâmica' que auxiliasse o gerenciamento, preservação e melhor aproveitamento do solo, referencia, sob a noção de 'equilíbrio', sua classificação ambiental de três estágios: meios estáveis (evolução do modelado lenta), meios intergrades (transição entre o estável e instável) e meios instáveis (onde predominam a morfogênese).

Embora os modelos ambientais tenham constituído importantes ferramentas para o planejamento de áreas para uso e ocupação, pela relativa predição dos fenômenos, processos etc, estes entendimentos mais voltados aos mecanismos de controle e estabilização penaram para captar os processos humanos de transformação da paisagem, com dinâmicas mais caóticas e imprevisíveis, enquanto fatores influentes nos sistemas ambientais. Por conta disso, os resultados obtidos pela modelagem, expressos, por exemplo, em cartas temáticas e caracterização das áreas e processos, não bem 
conseguiram se reverter em formas de intervenção efetiva. Isso decorrente, muitas vezes, à ofuscação que as pertinências das preferências humanas causam, como, por exemplo, para a estruturação urbana e expansão agrícola, decorrentes de processos sócio-econômicos sob um substrato cultural, que, contudo, não são bem captáveis pelos modelos ambientais sistemicamente pautados.

Entendimentos advindos dos avanços do século XX trouxeram elementos de flexibilização entre os resquícios dicotômicos que balizam as unilateralidades nas ações reflexivas e operacionais entre as formas de conhecimento na ciência em geral, Geografia Física e geomorfologia, e promovem perspectivas de diálogos entre estas para um melhor tratamento das multidimensões e domínios que foram reconhecidos como não-redutíveis nos fenômenos em geral.

\section{ASPECTOS CIENTÍFICOS DO SÉCULO XX: O PROCESSUAL E O OBJETO COMPLEXO}

Em ampliação à visão estática e mecânica das heranças modernas, o século XX demonstrou, cientificamente, uma realidade fundamentalmente processual, isso tanto com respeito às características e propriedades do objeto do conhecimento (ontológico), quanto em relação à forma de conhecê-lo (epistemológico). Sem necessariamente estabelecer uma ruptura entre os avanços do século XX com os do século XIX, já que se compõem de continuidades e descontinuidades, a Teoria da Relatividade e Teoria Quântica representam exemplares desenvolvimentos que reconheceram tal processualidade. Um dos aspectos essenciais da Teoria da Relatividade de Einstein é ter ela questionado idéias tidas como praticamente evidentes, que eram o Espaço e Tempo Absolutos de Newton. Colocou-se em xeque não somente a coisa estudada, mas principalmente a capacidade do espírito humano de questionar suas próprias estruturas do conhecimento.

A estrutura do espaço deixou de ser um meio vazio independente dos corpos que o 'habitavam', para referir-se a uma extensão relativa à realidade material destes corpos que o comporiam e dariam sua realidade. Retirada as referências absolutas do conhecimento científico, nenhuma teoria científica poderia, a partir de então, se impor como absolutamente objetiva em suas referências, e universal em suas explanações (JAPIASSU, 1981, p.21). A objetivação prevaleceu sobre a objetividade, no sentido que, determinar um caráter objetivo não mais significava basear-se em fundamentos puros e absolutos, mas sim provar que se poderia aplicar corretamente um método que já deu provas de seu valor lógico, mas que, contudo, não deixava de ser uma criação do espírito humano (BACHELARD, 1977, p.31-36). Na Geografia isso influenciou no período de consolidação da Nova Geografia, com a concepção de espaço não se limitando mais somente ao seu aspecto 'geométrico', mas incluindo também o 'cinemático', sobre o movimento em condições não determinadas, e o 'dinâmico' sobre o movimento em condições determinadas (OLIVEIRA, 1972, p.12-13). Esclareceu-se, pela Relatividade, que nada no mundo físico poderia mais se caracterizado como puramente corológico ou cronológico, tanto, para a diferenciação espacial, quanto, para a narrativa temporal.

A Teoria Quântica, por seu lado, trouxe, em analogia, a 'relativização' ontológica e epistemológica microscópica. Destacaram-se as incertezas descritivas, que impossibilitou a realização de um conhecimento objetivo da partícula atômica (elétron). Os corpos apresentaram-se como fundamentalmente interconectados pelos domínios e 
escalas físicas. Realçou-se, também, a impossibilidade de se separar o objeto do seu método de inquérito devido ao continuum ontológico e epistemológico que se estabelece no inquérito quântico. Isso por que a propriedade (ontológico) do elétron (onda ou corpúsculo) só pode ser definida pelo sujeito pela aplicação de um método (epistemológico). A física quântica, em acompanho às considerações da Teoria da Relatividade, reconheceu que a matéria, o objeto (físico) do conhecimento, não pode ser concebida como um objeto estático e ordenado, mas sim, como uma entidade fundamentalmente processual (HEISENBERG, 1981, p.94). Em ampliação à visão realista que dava ao sujeito direta ligação com o real, o contexto que envolveu a Relatividade e Teoria Quântica demonstrou que o conhecimento é inevitavelmente mediado de forma indireta e incerta pela Teoria.

Em reflexão à tais movimentações, e apresentando seus próprios desenvolvimentos, o contexto da Filosofia da Ciência do início do século, também apresentou um conhecimento fundamentalmente processual. Considerações como as Incompletudes lógicas e formais, com Tarski e Gödel, demonstrando que, tanto a lógica, quanto a matemática, carecem de fundamento final e definitivo, aliado à maior discussão epistemológica do século XX, promovida por figuras como Popper, Kuhn, Lakatos, Horton etc, sobre a organização e evolução do conhecimento, são alguns dos que expressaram a consciência da processualidade do conhecimento científico (LAKATOS \& MUSGRAVE, 1979, p. 343). As modernas Teorias Sistêmicas, pelas Teoria Geral dos Sistemas de Bertalanffy, Cibernética e Teoria da Informação de meados do século XX, emergidas no contexto da Big Science patrocinada pelas Guerras Mundiais e expansão capitalista, e que tiveram o problema biológico de descrição do ser vivo como referência descritiva, foram as que se apresentaram como fornecedores de arcabouço de noções (organização, código, feedbacks, estrutura, informação etc) e entendimentos mais condizentes com uma realidade processual.

Essas reflexões foram aproveitadas pela ciência em geral. Na Geografia repercutiram principalmente a partir da década de 50 nas discussões em torno da Revolução Quantitativa e Teorética. A noção de paradigma de Thomas Kuhn como referência de mudança de conduta epistemológica, o método hipotético-dedutivo, refinado por Popper, foi o método adotado. As considerações da teoria quântica vieram como forma de se reinterpretar a noção de determinismo, causalidade etc, de forma a inserir os elementos humanos com suas indeterminações e ambigüidades. As teorias sistêmicas, munidas de ferramentas matemáticas e estatísticas, que se espraiaram para a ciência em geral, constituíram, em contexto, uma abordagem unificadora das descrições científicas pelas diversas disciplinas, com a Geografia tomando-as como referencial teórico (CHRISTOFOLETTI, 1976, p.3-33). Os estudos geográficos começaram a também voltar o foco para os processos espaciais a partir de uma abordagem mais nomotética (leis e regras), pela elaboração de um corpo teórico para a construção e manuseio de modelos, denominado de análise espacial.

Mas foi a partir de avanços científicos ocorridos na segunda metade do século que a processualidade se estabeleceu de forma definitiva e se difundiu nas duas últimas décadas do XX para a ciência em geral. Promotora de significativa movimentação paradigmática esses foram os que reconheceram o objeto do conhecimento como uma entidade 'complexa', flexibilizando, na mesma esteira, muitas das balizas duais que são vividas em reflexão e conduta de formas dicotômicas pela ciência e Geografia na modernidade. A partir de aspectos dos avanços ligados aos Sistemas dinâmicos nãolineares e Física do não-equilíbrio pode-se, de forma básica, conectar-se com os 
Sistemas dinâmicos Complexos e alguns dos principais entendimentos do contexto da Complexidade.

No campo dos sistemas dinâmicos não-lineares, que são a extrema maioria dos sistemas da natureza, ficou observado que pequenas perturbações poderiam gerar, em longos períodos, grandes perturbações. Um dos estudos primordiais no campo da metereologia observou que pequenas diferenças na entrada de um simulador atmosférico poderiam gerar, com o decorrer do tempo e interações espaciais, significativos desvios de trajetória. Estes desvios estão associados às fontes de bifurcações e inconstância evolutiva do sistema, denominado "sensibilidade às condições iniciais", e que reconhecem, em extrapolação para os diversos campos, que a maioria dos sistemas dinâmicos da natureza não são previsíveis à longos prazos. Isso decorre que, das constantes e infinitas interações espaciais que um sistema dinâmico não-linear realiza com o seu ambiente, presencia-se instabilidades e flutuações que geram bifurcações na evolução dos sistemas. Isso torna o sistema, apesar de sensível, não dependente das condições iniciais, ou determinado por elas, possuindo 'liberdade' de evolução e imprevisibilidade quando se considera longos períodos. $\mathrm{O}$ 'efeito borboleta' é uma das proposições mais conhecidas dos sistemas não-lineares, denominado de Ciência do Caos, com a possibilidade hipotética de que as batidas das asas de uma borboleta no Atlântico possam causar um furacão no Pacífico. A interconectividade dos corpos trazida pela teoria quântica converge com os ensinamentos de que, nas hierarquias escalares dos sistemas, o local, individual e contingente, pode, de acordo com a situação, muito bem influenciar as escalas da totalidade, do conjunto e do geral.

$\mathrm{Na}$ física do não-equilíbrio, estudos nos sistemas termodinâmicos longe-doequilíbrio observaram que as instabilidades e flutuações produtoras de entropia, inerentes aos sistemas não-lineares, que são a extrema maioria dos sistemas da natureza, não o levaria apenas à degradação irreversível, mas também representaria uma condição construtiva e de transformação no sistema. Ficara constatado que, sob determinadas condições de desequilíbrio termodinâmico, a matéria poderia adquirir propriedades criativas, e, caso envolvesse um significativo número de componentes individuais estruturados, interagindo e co-existindo entre si, poderiam surgir espontaneamente comportamentos coerentes em nível macroscópico, como é o caso, em extrapolação, dos átomos, vida, sociedades, estrelas, denominadas de estruturas dissipativas (PRIGOGINE, 1996, 199p.). A não-linearidade das interações espaciais, e as conseqüentes flutuações, constituiriam as procedências das bifurcações e transições de comportamento vivenciadas pelo sistema em sua evolução (PESSOA JUNIOR, 2006, p.44).

A consideração da historicidade, pela produção irreversível de entropia e bifurcação a partir das interações espaciais, e das instabilidades é essencial para a compreensão destas estruturas, pois estas propriedades caracterizam as potencialidades criativas e de transformação do sistema. A historicidade fundamenta uma descrição evolucionista, entendido como um fluxo unidirecional e irreversível ligado à produção de entropia (dissipação em calor), que pode ser associada à uma Flecha do Tempo embora ainda não se possa afirmar o caráter ontológico da irreversibilidade temporal, mas sim, sua importância epistemológica. As pequenas mudanças nas condições iniciais ocasionadas pelas flutuações e instabilidades, tornam imprevisíveis os comportamentos nos pontos de bifurcações que originam os desvios. Estes podem ir amplificando a variação, de maneira que, com o decorrer do tempo, o sistema perde a memória de suas condições iniciais; e de forma inversa, também não torna possível uma previsão objetiva 
do futuro, que passa a ser estabelecido apenas em termos de cenários probabilísticos associados a uma rede complexa de causalidades, corroborando as idéias de multicausalidade e de que o futuro está sempre em vias de criação.

A determinação, por seu lado, continua sendo responsável pela manutenção da ordem e regularidade no sistema, e, mesmo que atravessada por instabilidades, ainda há a conservação do caráter determinístico do sistema; porém, esta, nas diversas escalas é sempre nutrida pela indeterminação, que a mantém numa relação de concorrências, antagonismos e complementaridades (em termos morinianos) que permitem manter o dinamismo de sua organização em estado criativo. O criativo, nesta perspectiva, pode ser considerado como a produção do novo, resultado de um processo de transformação organizacional, que se caracteriza pela formação de estruturas novas e funcionamentos novos, evidenciando que a criação é uma emergência do sistema (D'OTTAVIANO \& BRESCIANI FILHO, 2004, p.19).

$\mathrm{Na}$ física, a distinção linearidades/não-linearidades representa uma das manifestações do dualismo do conhecimento ocidental - necessidade/liberdade, determinação/contingência, natural/humano, sujeito/objeto (MORIN, 2001, p.270). Com o retorno das não-linearidades/contingências/liberdades como inerentes à dinâmica física e descritiva da natureza, associado à noção de caos determinístico, ocorre perspectivas de reconciliação sobre a dinâmica do objeto para com as manifestações expressamente humanas, como a criatividade, que antes foram rechaçadas e dissolvidas nas leis e regras gerais de um conhecimento mais absoluto. Assim, nessa esteira, flexibilizam-se os 'aprisionamentos' escalares das abordagens, com tanto o geral-total influindo sobre o particular-local, quanto vice-versa, com o singular e particular podendo adquirir grandes proporcionalidades em relação ao geral-total. A geometria Fractal é uma das expressões espaciais de como as perturbações se interpenetram pelas diversas escalas espaçotemporais.

Desse contexto derivou-se a central noção de auto-organização. A idéia de auto-organização derivou-se, assim, a partir do reconhecimento das instabilidadesflutuações (física), ou ruídos (informação), como fontes de ordenação e complexação na evolução dos sistemas dinâmicos. Portanto, só pode haver auto-organização em sistemas que funcionam longe-do-equilíbrio, ou seja, em regime de trocas de energia, matéria e informação advindas do ambiente, fontes de sua manutenção organizacional. O prefixo "auto", nesta perspectiva, corresponde à idéia de referência a si mesmo e que caracteriza a autonomia do sistema em relação ao ambiente. Em seu sentido básico pode-se dizer que há auto-organização toda vez que ocorrer a reestruturação de uma forma ao longo de um processo, no qual essa reestruturação se deverá principalmente pelo dinamismo do próprio processo, e somente em grau menor devido às suas condições de partida e intercâmbios com o ambiente (LUZZI \& VASCONCELLOS, 1999, p.19, DEBRUN, 1996, p.04).

Noções como a auto-organização oferece perspectivas conciliatórias entre as dicotomias ontológicas e epistemológicas entre universal/singular, nomotético e idiográfico, onde, conforme já exposto, processos gerais idênticos são susceptíveis a produzir efeitos e estruturas singulares e diferentes em função dos diversos valores dos parâmetros e diversas condições iniciais que controlam sua evolução. Assim, a liberdade de escolha dos atores individuais, e a possibilidade de 'surgir' e 'existir' entidades autônomas e singulares, como são as diferenças culturais dos indivíduos e sociedades, não podem mais serem excluídas das explicações pelo argumento de que são incompatíveis com a produção, ou como efeito, das regularidades dos processos. 
Os denominados sistemas dinâmicos complexos e a Complexidade são então, as expressões conceituais mestras de todo este contexto que reconheceu o objeto do conhecimento como uma entidade complexa. Isso se deu pelo re-encantamento, desde o fim do século XIX, das não-linearidades (desordem), associados a caos, entropias, turbulências, bifurcações, quebras de simetrias, catástrofes, rupturas etc, no âmbito do conhecimento científico. O caráter 'complexo' advém da infinita gama de interações entre domínios (esferas de ações) e dimensões não redutíveis, nem em manifestação, nem em entendimento um aos outros. Os sistemas complexos, que são a extrema maioria dos sistemas da natureza, não detêm, assim, somente aspectos físicosmecânicos, mas também transferências de informação-sinais, que possibilita o sistema mudar e se adaptar ao ambiente, a partir de suas relações internas e externas. Isso realçou a não-redutibilidade de manifestação e descrição no estudo de muitos fenômenos físicos e emergentes na natureza.

Essas interações, consigo mesmo e ambiente, ocorrem de maneira não-linear, com pequenas causas podendo gerar amplos efeitos, ou seja, com o elemento-indivíduo podendo exercer amplas influências no sistema como um todo, porém, desde que as interações sejam suficientemente ricas e amplas para que isso ocorra, visto que, de uma forma geral, as maiores influências mútuas das interações ocorrem mesmo nas vizinhanças imediatas dos elementos e não muito se expandem.

Outro aspecto de destaque nos sistemas complexos é que operam sob condições distantes do equilíbrio termodinâmico, em constante fluxo de energia como forma de manter sua organização em patamares estáveis, ou seja, fugindo do equilíbrio definitivo (termodinâmico). As não-linearidades, associadas à dissipação de energia (produção entropia) e às instabilidades, flutuações, bifurcações, catástrofes etc, corroboram o caráter histórico dos sistemas complexos. Isso torna o passado de correlações do sistema co-responsável pelo seu comportamento atual, exigindo a incorporação da dimensão temporal em sua descrição dinâmica, que tradicionalmente é simétrica (CILLIERS, 2000, p.03-24).

A chamada Complexidade apresenta-se, então, como esse contexto de reconhecimento do objeto do conhecimento como uma entidade que tem qualidade ou estado 'complexo', com o complexo sendo caracterizado basicamente como algo composto da inter-relação de muitas partes (ou elementos) e padrões variados. A noção da Complexidade encontra-se na encruzilhada entre as noções de ordem e desordem, uma vez que, dependendo do nível de representação e escala adotada, um sistema pode ser considerado mais ou menos ordenado ou desordenado. Deste panorama pode-se, por exemplo, discernir os veios da Teoria e Ciência da Complexidade. A chamada Ciência da Complexidade refere-se a um termo conotativo que especifica uma forma particular de inquérito deste panorama. Sua firmação no panorama do conhecimento pode ser caracterizada como uma 'nova' ciência não somente por apresentar novas abordagens para o estudo da complexidade do mundo, mas principalmente por desenvolver novos métodos científicos para o estudo de suas regularidades, regras e padrões, agora não mais como Leis eternas.

As manifestações associadas às noções de caos, instabilidades, fractais, bifurcações, flutuações, criticalidades etc, que envolvem descrições acontecendo em espaço de fase, traçando atratores estranhos, e recorrendo a expoentes, como o de Lyapunov, etc são algumas das recentes denominações e ferramentas analíticas que se constituíram e acompanham os refinamentos e avanços descritos. $\mathrm{O}$ desenvolvimento dos computadores, pertencente ao movimento de constituição deste panorama, 
potencializou a modelagem matemático-estatística dos sistemas reais visto realizarem densos cálculos e simulações.

A Teoria da Complexidade, por seu lado, tem como problema fundamental a incompletude do conhecimento. Reconhece-se que é impossível a realização de um conhecimento total e monístico de qualquer sistema da natureza, em vista de sua nãoquantificável e reduzível complexidade ontológica e epistemológica, além de nossa inevitável e irremediável limitação enquanto conhecedores reais. Nesta situação, um 'pensamento' complexo busca estrategicamente somar o que no pensamento simplificador tradicional (que praticamos) se excluiu e mutilou. $\mathrm{O}$ arcabouço científico constituído de uma realidade processual dissolveu, assim, as referências duais da modernidade, que teimam em viver dicotomicamente e referenciar a fragmentação do conhecimento, em favor de uma perspectiva organizacional com paralelos na Biologia (MORIN, 2002, 480p.).

\section{A TEMÁTICA DA GEOGRAFIA FÍSICA EM PERSPECTIVA}

A ciência em geral e a Geografia têm se nutrido do contexto dos avanços descritos. Isso pode ser comprovado por simples pesquisa na internet. Os diversos fenômenos geográficos estão sendo reconhecidos como apresentando propriedades características dos sistemas complexos, como instabilidades, flutuações, bifurcações, imprevisibilidades, emergências, auto-organização etc. Após dois séculos de estudos balizados no equilíbrio, em referência aos padrões estáticos, que não viam além dos mecanismos de ajustamento dos comportamentos (feedback negativo), a Geografia agora se reconhece, também, como tratando em sua maioria de sistemas não-lineares e distantes do equilíbrio numa perspectiva mais processual, orgânica, evolutiva e metodologicamente complementar.

Com realce aos mecanismos de desvio, transformação e criação, os chamados feedbacks positivos, agora, os geógrafos ligados à corrente analítico-sistêmica, necessitarão, por exemplo, se esforçar para estudar também aspectos como as emergências de estruturas, com foco direcionado para o encontro de novos tipos de padrões a serem observados, descritos e criados. Pode-se, nesta perspectiva, adiantar algumas direções de enriquecimento da disciplina: - sensibilidade às condições iniciais da maioria dos processos espaciais, - os múltiplos níveis escalares de estados ordenados perpassados por estados caóticos, - o desencadeamento genético de estados ordenados em escalas superiores a partir das instabilidades, flutuações, bifurcações etc em escalas inferiores em sistemas espaciais - além da consensual imprevisibilidade em longo prazo da maioria desses sistemas (DURAND-DASTÈS, 1991, p.312).

Nos diversos campos das Ciências da Terra associados à Geografia Física como a climatologia, geologia, geomorfologia, pedologia, hidrologia etc, todas estão, em maior e menor grau, se nutrindo das novas ferramentas e abordagens advindas da Complexidade.

Nos sistemas climáticos metodologias têm sido propostas para a quantificação do caos pela formulação de equações, tabulações e tratamentos de longas séries de dados temporais, demonstrando, em simulação, bacias de atração e susceptibilidade às condições iniciais que podem gerar diferentes representações e previsões para o sistema. Esta ultima propriedade garante sua pertinência pelo fato dos modelos de representação climática, mesmo com potentes simuladores, não conseguirem abarcam os múltiplos processos e fatores que influenciam as mudanças de estado climático. Por esta 
limitação, se tem sugerido que a representação em espaços de fase possa ganhar complementos 'análogos' empíricos (por exemplo, descrições de campo) para a cobertura dos dados e graus de liberdades espaço-temporais não facilmente modeláveis e que possam vir a influenciar a convergência de estados em atratores. Busca-se, assim, complementos de formas de conhecimentos classicamente vividos como dicotômicos, como o nomotético, das dinâmicas caóticas descritas em termos de leis gerais nãolineares, e o idiográfico, por abordagens descritivas sobre as particularidades das manifestações influentes (WASHINGTON, 2000, p.500-512).

Em relação ao substrato geológico, no contexto dinâmico da Geologia, apesar das dificuldades envolvidas na aferição de dados de longos períodos, as propriedades dos sistemas dinâmicos não-lineares, com o caos, instabilidades, bifurcações etc estão sendo sugeridas como uma descrição mais fidedigna dos processos dinâmicos pretéritos que têm sido supostos, e dos atualmente responsáveis pelas feições observadas. Questões como a impossibilidade de previsão com grande antecedência de fenômenos como terremotos e erupções vulcânicas, que atualmente é de apenas alguns segundos, a configuração morfológica do terreno exposto nas paisagens, na disposição de rochas nas vertentes (matacões, por exemplo), e a morfologia resultante dos intemperismos (desgaste) e erosões de materiais todos trazem em suas configurações expressões dos dinamismos associados ao caos determinístico. A auto-organização ainda assim pode ser captada dentro de uma perspectiva histórico-interpretativa, aplicando, por exemplo, medidas de graus de organização das feições geológicas e daí traçar sua evolução, observando se há ou não um aumento da organização interna ao sistema (PHILLIPS, 2007, s/p).

Para os estudos pedológicos (solos) as influências e pertinências dos conceitos, abordagens e ferramentas formais dos sistemas complexos também já estão bem declaradas (CULLING, 1988, p.619-648). A incerteza determinística tem oferecido, por exemplo, perspectivas mais amplas para o entendimento das diversidades $\mathrm{e}$ variabilidades espaciais de propriedades métricas, composição e disposição dos horizontes nos perfis longitudinais dos solos. Tal abordagem não vem em oposição à visão reducionista tradicional que oferece um contexto donde se tiram deduções para a compreensão dos sistemas e perfis pedológicos. Bem aplicadas às escalas regionais, as visões tradicionais baseiam-se no balanço entre os fatores de formação: clima, material de origem (geologia), relevo-declividade, matéria orgânica (vegetação). Agora, no contexto complexo, esta abordagem pode ser complementada pela abordagem da incerteza determinista com entendimentos que possibilitam refinar as descrições com respeito às inúmeras particularidades na disposição dos horizontes observados nos perfis pedológicos à escala local, onde a morfologia e disposições das camadas apresentam especificidades em cada vertente e em cada transecto traçado.

No campo da Hidrologia, os processos acerca da natureza de ocorrência, circulação e distribuição da água na dinâmica do planeta apresentam óbvias conexões com os sistemas dinâmicos complexos. Foi, inclusive, a partir dos refinamentos nos entendimentos da dinâmica dos fluídos que se estabeleceram as principais investigações que legitimaram a importância dos processos associados à complexidade na descrição comportamental e evolutiva dos sistemas em geral. Estudos de séries de dados e observações empíricas bem demonstram a presença da incerteza determinística nos escoamentos e turbulência nos fluxos de rios. E, considerando que o escoamento é uma das mais importantes forças direcionadora para as intensidades de muitos dos outros processos que ocorrem no sistema de drenagem, como exemplo, a concentração e 
interação entre as cargas de sedimentos, este também, enquanto dinâmica de um fluido, exibe dinâmicas não-lineares. Como tradicionalmente a maioria dos conceitos e métodos utilizados pela hidrologia é de caráter linear, os autores envolvidos já reconhecem que um dos desafios é justamente a adaptação dos estudos hidrológicos para com as novas abordagens e métodos não-lineares e estabelecer os vínculos entre os resultados destes métodos e a predição de comportamentos do sistema (SYVAKUMAR, 2007, p.969-979).

A abordagem fractal, enquanto veio deste contexto, possui ampla aplicação no campo das ciências da Terra em geral, em disciplinas como Geofísica, Petrologia, Mineralogia, Sedimentalogia, Tectônica, Metereologia, Climatologia, Geomorfologia, Hidrogeologia, Oceanografia, Geomecânica, Geoquímica, Pedologia etc (CHRISTOFOLETTI \& CHRISTOFOLETTI, 1995, p.227-264).

A Geomorfologia é um dos campos da temática da Geografia Física com maior aprofundamento teórico-metodológico, por isso, sua situação será aqui realçada. As propriedades e noções associadas aos sistemas dinâmicos complexos apresentam-se de forma marcante e tem sido requerido para a descrição da dinâmica do modelado terrestre (WERNER, 1999, p.102). Tradicionalmente embasada na noção de equilíbrio, sob a referência do paradigma da ordem e estabilidade soberanas, os avanços científicos ligados à Complexidade trouxeram importantes repercussões que são tratadas principalmente como evoluções nas concepções e métodos utilizados pela Geomorfologia. Isso porque muitos dos conceitos e abordagens fundamentais podem, realmente, ser reinterpretados sob a estrutura dos sistemas dinâmicos não-lineares e física do não-equilíbrio (HUGGETT, 1988, p.45-48). O conceito de equifinalidade, por exemplo, que implica que diferentes processos ou paisagens, com históricos diferentes, produzirão, como resultado, formas similares entre si, não pode ser aplicado em sistemas caóticos. Contudo, promove-se uma extensão do conceito, oferecendo a promessa de inserir e explanar os elementos 'aleatórios' e com padrões complexos em termos determinísticos relativamente simples. A observação e explanação sobre ordenações e caoticidades ocorrem sempre em dependência da escala considerada, com os sistemas geomorfológicos podendo apresentar ambos os comportamentos, direcionando-se, ou não, ao equilíbrio. Assim, em amplas escalas podem apresentar-se como equilibrados e previsíveis, como a evolução regional dos relevos, enquanto em áreas restritas, nos processos erosivos locais, apresentar-se como caóticos e não previsíveis em suas decorrências (PHILLIPS, 1992, p.227).

A auto-organização tem sido apreendida como expressando muitas das propriedades dinâmicas do modelado terrestre. Phillips (1999b, p.467) distingue onze diferentes conceitos de auto-organização na literatura corrente que tem sido relevante e aplicados nos estudos da paisagem. Citemos algumas concepções: auto-organização como a manutenção de um steady-state interno e autônomo; como ajustes mútuos; como tendência à entropia mínima; tendência à entropia máxima; como padrões de formação surgida de dinâmicas caóticas (caos determinístico), ou do crescimento finito de instabilidades; cita-se também a auto-organização como tendência a envolver direções a estados estruturais críticos (criticalidade auto-organizada); e como formação de padrões autogenéticos na natureza e em modelos de simulação.

Com a repercussão do contexto complexo houve, na Geomorfologia, a revisão da base dinâmica dos estudos pautados nos processos. Com fundos em Strahler, neste autor as heranças de uma concepção mecanicista voltada ao equilíbrio é bem característica, havendo, portanto, a pertinência da revisão em sua base dinâmica para 
uma concepção mais fundamentalmente processual (RHOADS, 2006, p.14-300). Essa revisão repercute em aspectos primordiais como: (1) a ultrapassagem e eliminação da dicotomia entre uma pesquisa pautada no processo (funcionais, a-históricas, padrões gerais) e as pesquisas geo-históricas de fundo empírico-descritivo, em favor de uma perspectiva organizacional, enfatizando o desvendamento dos mistérios envolvidos nas dinâmicas morfogenéticas inerentes às interações dos sistemas naturais complexos (SPEDDING, 1997, 261-265). (2) Há a acomodação da explanação qualitativa dos fenômenos, dando maior liberdade aos pesquisadores para recorrer às considerações interpretativas e históricas. As manifestações e estudos geomorfológicos tornam-se fundamentalmente espacial e temporalmente localizados (singulares).

(3) Flexibiliza-se as hierarquias das escalas espaço/temporais. Dissolve-se a rigidez fixada entre os níveis de causalidade, propostas por Schumm e Litchy, sobre as variáveis dependentes, independentes e irrelevantes dos processos e formas. Os 'aprisionamentos' temporais não podem mais ser rigidamente vividos, as influências entre as escalas, grandes áreas-longos tempos e pequenas áreas-curtos tempos, podem até ser 'relaxadas', no sentido, de dar menos peso sobre suas influências, mas não podem mais ser ignoradas completamente. Essa perspectiva enfatiza a pertinência de comparações e complementos entre métodos alternativos, somando entendimentos das abordagens dinâmicas-funcionais e geo-históricas para uma mais completa compreensão dos fenômenos (LANE \& RICHARD, 1997, p.249-260). (4) E a detenção, potencialmente reconhecida, para ligar os estudos geomorfológicos aos de geografia humana, mas, para isso destaca-se a Geografia como um todo para o diálogo entre os conhecimentos.

Os avanços científicos ocorridos a partir das décadas de 50-60, mas vividos na geografia principalmente depois da década de 80 , trouxeram uma sobrevalorização do trabalho de campo na geografia física. Nota-se que, em áreas como a geomorfologia, os discursos destas novas tendências vêm se estabelecendo com similaridades aos argumentos das ciências sociais. Cabe a menção que a Geografia Física tem vivenciado nas últimas décadas uma reanimação das preocupações sobre as suas bases e influências filosóficas, procurando discutir fundamentos e ampliar as perspectivas em que estão pautadas (RHOADS \& THORN, 1994, p.90-101, BAUER, 1999, p.677-679, RHOADS, 1999, p.760-771, 2004, p.748-755, 2006, p.14-30). Isso tem ocorrido em consonância, mas não em prevalência, com as repercussões dos sistemas dinâmicos complexos. Pautadas em estruturas intelectuais mais amplas que as tradicionais, essas novas filosofias da geografia física enfatizam uma maior abertura para metodologias, epistemologias e ontologias alternativas para o tratamento da realidade (POWELL, 2002, p.265-266). Os geógrafos físicos começam, assim, a raciocinar os fenômenos considerando a combinação de ambos procedimentos, experimentais e interpretativos, fazendo os autores advogarem que se vive atualmente um período de "re-encantamento" (BAKER \& TWIDALE, 1991, p.73-100, PHILLIPS, 1999, p.759) das empirias pelas práticas de campo nas ciências da terra.

\section{CONSIDERAÇÕES FINAIS}

Os avanços científicos acontecidos no século XX e suas repercussões epistemológicas exigem maiores explorações dos geógrafos para a ampliação do arcabouço que conduz à reflexão e manuseio dos modelos. O contexto da Complexidade e Sistemas Dinâmicos Complexos são um destes que reclamam maiores contatos para 
com as noções, conceitos, técnicas e ampliações epistemológicas, principalmente em âmbito nacional. Aqui se direcionou os esforços para uma explanação geral e básica de algumas influências deste contexto em ramos da temática da Geografia Física.

Nos campos da Climatologia, Geologia, Pedologia, Hidrologia etc estão todos se nutrindo das novas noções e ferramentas para os estudos de seus objetos. A Geomorfologia, como um dos campos da Geografia Física e estudos ambientais com maior aprofundamento epistemológico, reconhece repercussões em suas bases de conduta reflexiva e prática, mas cujas decorrências só podem ser vislumbradas em perspectiva. As noções e ferramentas associadas ao contexto complexo, como caos, instabilidades, auto-organização, instabilidades, fractais etc estão sendo utilizados como uma mais refinada e adequada forma de se estudar os fenômenos geomorfológicos.

A perspectiva processual do final do século XX e início do XXI, dizendo respeito a aspectos fundamentais do estudo geomorfológico, e não para uma perspectiva em particular, dissolveu, flexibilizou e ultrapassou a dicotomia entre uma pesquisa pautada no processo (nomotético, funcionais, a-históricas, padrões gerais) e as pesquisas geohistóricas de fundos empírico-descritivos, mais idiográficos, em favor de uma perspectiva organizacional, com destaque para o inquérito dos processos envolvidos nas dinâmicas morfogenéticas dos sistemas naturais. Ocorre a acomodação da explanação qualitativa dos fenômenos, liberando, de forma definitiva, os pesquisadores a utilizarem abordagens mais interpretativas e históricas, em vista das manifestações e estudos tornarem-se fundamentalmente espaçotemporalmente localizados (singulares, particulares). Flexibiliza-se e dissolve-se a rigidez dos 'aprisionamentos' dos níveis de causalidades entre as hierarquias escalares - grandes áreas-longos tempos e pequenas áreas-curtos tempos -, com as influências mútuas entre as diferentes escalas não mais podendo ser ignoradas. Isso enfatiza a necessidade de comparações e complementos entre métodos alternativos para uma mais completa descrição do fenômeno. Neste caminho, essas ampliações destacam a importância da empiria e práticas de campo para a adequação dos estudos de Geografia Física para com os novos conceitos, noções e ferramentas disponíveis.

Esta básica apresentação contextual veio, enfim, como principal tarefa, para alertar os geógrafos nacionais para a necessidade de se retomar as discussões epistemológicas para com a riqueza advinda dos avanços científicos ocorridos no século $\mathrm{XX}$, e que trazem repercussões à nível fundamental para a Ciência e Geografia. Suas perspectivas vinculam-se diretamente à ampliação da funcionalidade e efetividade dos modelos e conhecimentos em resolver os problemas e desafios postos.

\section{BIBLIOGRAFIA}

BACHELARD, G. Epistemologia. Rio de Janeiro : Zahar editores, 1977, 196p.

BAKER, V. R., TWIDALE, C. R. The reenchantment of geomorphology. Geomorphology, Vol.4, 1991, p.73-100.

BERTRAND, G. Paisagem e geografia física global: esboço metodológico. Caderno de ciências da terra, São Paulo, n.13, 1972, 27p.

CHRISTOFOLETTI, A. As características da Nova Geografia. Boletim de Geografia Teorética. 1 (1) : Abril 1976, p.3-33.

CHRISTOFOLETTI, A. Geomorfologia. São Paulo : Ed. E. Blucher, 1980, 188p.

CHRISTOFOLETTI, A, CHRISTOFOLETTI, A. A abordagem fractal em Geociências.

Geociências, 14 (1), 1995, pp.227-264. 
CILLIERS, P. Complexity and postmodernism. Understanding complex systems. London and New York : Routledge, 2000, 156p.

CULLING, W. E. H. Dimension and entropy in the soil-covered landscape. Earth Surface Processes and Landforms, 13, 1988, pp.619-648.

D’OTTAVIANO, I. M. L., BRESCIANI, E. Sistêmica, auto-organização e criação. Revista Multiciência - Seção Rede Interdisciplinar, A mente humana, COCEN/UNICAMP, v.3, 2004, p.1-23.

DEBRUN, M. A idéia de auto-organização. In: GONZALES, M. E. Q., PESSOA Jr. Auto-organização, Coleção CLE 18, Campinas, 1996, p.3-23.

DURAND-DASTĖS, F. La notion de chaos et la géographie quelques réflexions. L'Espace géographique, n.4, 1991, pp.311-314.

HEISENBERG, W. Física e Filosofia. Brasília: Ed. Universidade de Brasília, 1981, $149 \mathrm{p}$.

HUGGETT, R. J. Dissipative Systems: implications for geomorphology. Earth Surface Process Landforms, vol. 13, 1988, 45-49.

JAPIASSU, H. Questões epistemológicas. Rio de Janeiro : Imago, 1981, 173p.

KENNEDY, B. Hutton to Horton: views of sequence, progression and equilibrium in geomorphology. Geomorphology, Vol. 5, Issues 3-5, August 1992, pp.231-250.

LAKATOS, I. MUSGRAVE, A. A crítica e o desenvolvimento do conhecimento. São Paulo : Ed. Cutrix : Ed. da Universidade de São Paulo, 1979, 343p.

LANE, S. N., RICHARDS, K. Linking river channel form and process: time, space and causality revisited. Earth Surface Processes and Landforms, vol.22, 1997, pp.249260.

LUZZI, R., VASCONCELLOS, A. R. Algumas considerações sobre a complexidade, auto-organização e informação. Campinas/SP.: UNICAMP, 1999, 108p.

MORIN, E. Ciência com Consciência. Rio de Janeiro : Bertrand Brasil, 1996, 336p.

MORIN, E. O Método Vol. 4 - As idéias. Porto Alegre : Editora Sulina, 2001, 320p.

MORIN, E. O método. Vol. 1 - A natureza da natureza. Porto Alegre : Sulina, 2002, 480p.

MORIN, E. LE MOIGNE, J. L. A inteligência da complexidade. São Paulo : Ed. Peirópolis, 2000, 263p.

OLIVEIRA, L. O conceito geográfico de espaço. Boletim de Geografia Teorética, 2, (4) : 1972, p.5-22.

PESSOA JUNIOR, O. Auto-Organização e complexidade: uma introdução histórica e crítica, In: http://www.fflch.usp.br/df/opessoa/AO\&C-text.pdf, acessado em 15/11/2006, 50p.

PHILLIPS, J. D. Nonlinear dynamical systems in geomorphology: revolution or evolution? Geomorphology, vol. 5, No.3-5, 1992, pp.219-229.

PHILliPS, J. D. Methodology, scale, and the field of dreams. Annals of the Association of American Geographers, Vol. 89, 1999, p.754-60.

PHILLIPS, J. D. Divergence, Convergence, and Self-Organization in Landscape. Annals of the Association of American Geographers, 89 (3), 1999b, pp.466-488.

PHILLIPS, J. D. Signatures of Divergence and Self-organization in Soils and Weathering profiles (Abstract). The Journal of Geology, Vol.108, 2000, pp.91-102. disponível In: http://www.journals.uchicago.edu/doi/abs/10.1086/314386, acessado em 09/07/2007.

POWELL, R. C. The Sirens' voices? Field practices and dialogue in geography. Area, $34.3,2002$, p.261-272. 
PRIGOGINE, I. O fim das certezas. Tempo, caos e as leis da natureza. São Paulo : Editora da UNESP, 1996, 199pp.

RHOADS, B. Beyond pragmatism: the value of philosophical discourse for physical geography. Annals of the Association of American Geographers. Vol.89, 1999, p.760771.

RHOADS, B. L. Whither Physical Geography? Annals of the Association of American Geographers, 94 (4), 2004, pp.748-755.

RHOADS, B. L. The Dynamic Basis of Geomorphology Reevisioned. Annals of the Association of American Geographers, 96 (1), 2006, pp.14-30.

RHOADS, B., THORN, C. E. Contemporary Philosophical Perspectives on Physical geography with emphasis on geomorphology. Geographical Review, vol.84, n.1, Jan.1994, p.90-101.

SACK, D. New wine in old bottles: the historiography of a paradigm change. Geomorphology, Vol. 5, Issues 3-5, August 1992, pp.251-263.

SCHUMM, S. A., LICHTY, R. W. Tempo, espaço e causalidade em geomorfologia. Notícias Geomorfológicas, Campinas, 13 (25) : jun.1973, pp.43-62.

SANTOS, B. S. Um discurso sobre as ciências. Porto.: Afrontamento, 1998, 59p.

SIVAKUMAR, B. Nonlinear determinism in river flow: prediction as a possible indicator. Earth Surface Processes and Landforms, 32, 2007, pp.969-979.

SPEDDING, N. On Growth and Form in Geomorphology. Earth Surface Process and Landforms, Vol.22, 1997, pp.261-265.

TRICART, J. Ecodinâmica. Rio de Janeiro, IBGE, Diretoria Técnica, SUPREN, 1977, 91p.

VASCONCELlOS, M. J. E. Pensamento Sistêmico: o novo paradigma da ciência. Campinas : Papirus, 2002, 268p.

WERNER, B. T. Complexity in Natural Landform Patterns. Science, Vol.284, 2 April 1999, pp.102-104.

WASHINGTON, R. Quantifying chaos in the atmosphere. Progress in Physical Geography, 24, 4, 2000, pp. 499-514. 